\title{
Prevalence and treatment of common mental disorders in the English national population, 1993-2007
}

Nicola Spiers, Tarik Qassem, Paul Bebbington, Sally McManus, Michael King, Rachel Jenkins, Howard Meltzer* and Traolach S. Brugha

\section{Background}

The National Psychiatric Morbidity Surveys include English cross-sectional household samples surveyed in 1993, 2000 and 2007.

\section{Aims}

To evaluate frequency of common mental disorders (CMDS), service contact and treatment.

\section{Method}

Common mental disorders were identified with the Clinical Interview Schedule - Revised (CIS-R). Service contact and treatment were established in structured interviews.

\section{Results}

There were 8615, 6126 and 5385 participants aged 16-64. Prevalence of CMDs was consistent (1993: 14.3\%; 2000:

16.0\%; 2007: 16.0\%), as was past-year primary care physician contact for psychological problems (1993: 11.3\%; 2000:
12.0\%; 2007: 11.7\%). Antidepressant receipt in people with CMDs more than doubled between 1993 (5.7\%) and 2000 (14.5\%), with little further increase by 2007 (15.9\%). Psychological treatments increased in successive surveys. Many with CMDs received no treatment.

\section{Conclusions}

Reduction in prevalence did not follow increased treatment uptake, and may require universal public health measures together with individual pharmacological, psychological and computer-based interventions.

\section{Declaration of interest}

None.

\section{Copyright and usage}

(c) The Royal College of Psychiatrists 2016.
Common mental disorders (CMDs) have significant economic and social costs ${ }^{1}$ and are major contributors to the burden of disability in England. ${ }^{2}$ There has been concern, especially since the 1970 s that the prevalence of mental disorders is increasing., ${ }^{3,4}$ However, although the prevalence of depressive disorder obtained in successive psychiatric community surveys has been relatively stable in the UK and the USA, ${ }^{5,6}$ thresholds for diagnosis by primary care physicians have become progressively lower. ${ }^{7}$ The Adult Psychiatric Morbidity Survey programme (APMS; http:// www.mentalhealthsurveys.co.uk/) includes repeated large-scale cross-sectional household surveys of the British adult population, carried out in 1993, 2000 and 2007, using standardised and essentially unchanged methods. ${ }^{8-11}$ The programme was developed to monitor the mental health of people living in private households, with a view to informing government mental health policy. In consequence, we may compare rates of mental disorders, health service use and treatment delivery at different time points over a 15-year-period. As the 2007 survey covered only England, we restricted the current analyses to the English population in each survey. Recent analyses of the APMS found no clear secular trend in CMD in general or in depressive episode in particular. ${ }^{6}$ Increasing use of hypnotics in the APMS has been reported elsewhere. ${ }^{12}$ We have previously examined trends between 1993 and $2000 .{ }^{13}$ In the current study, we used cross-sectional data to compare rates of health service use for a psychological problem for those with and without CMD in the three adult surveys spanning 1993 to 2007. This allowed us to identify changes in the use of psychoactive medication, and provides context for assessing the impact of the Improving Access to Psychological Therapies (IAPT) programme. ${ }^{14}$

*Deceased

\section{Method}

\section{Data sources}

The methods used for the three national surveys have been described in detail elsewhere. ${ }^{9-11}$ Although improvements were made in successive surveys, the emphasis was on using identical instruments wherever possible. Adults living in private households were sampled using population-based multiphase probability sampling, and interviewed in the first phase by lay interviewers. The stratification of primary sampling units by region and socioeconomic characteristics was more fine-grained in 2007 than in 2000 and 1993, but, in each case, the data can be weighted to represent the English household population at the time of the survey. Sample sizes were designed to provide the statistical power required for estimating the prevalence of rare disorders (0.5$1.0 \%$ ) by age, gender and region, and thus to have sufficient power to analyse prevalence of health service use by age, gender and survey.

Data on health service use were derived through directly comparable questions in all three surveys. Fieldwork was carried out between April and September 1993, between March and September 2000, and between October 2006 and December 2007. Response rates for the household APMS were 79\% in $1993,69 \%$ in 2000 and $57 \%$ in 2007 . The paper and pencil questionnaires used in 1993 were replaced by computer-assisted interviewing in subsequent surveys; this is not thought to affect the results substantially. ${ }^{15}$ Ethical approval for the Adult Psychiatric Morbidity Survey (APMS) 2007, was obtained from the Royal Free Medical School Research Ethics Committee, London, England. The APMS surveys in 1993 and 2000 were also granted research ethics approval. ${ }^{10,11}$ 


\section{Measures}

The surveys collected information about the use of services and receipt of treatments. In 1993 and 2000, all participants were asked the question: 'Are you taking any pills or tablets or any other medicine by mouth which have been prescribed for you?' In 2007, the question took the form: 'Are you taking any pills or tablets which have been prescribed for you?' In all three surveys participants were also asked whether they were having a regular course of injections. The medicines were coded according to British National Formulary categories ${ }^{16}$ during data entry subsequent to the interview in the 1993 and 2007 surveys and at interview in the 2000 survey. In 1993 and 2000, all medications being taken were elicited and coded. In 2007, participants were asked whether they were taking any psychoactive medication using show-cards with all commonly prescribed medications. ${ }^{17}$ In the current study we analyse two groups: (a) antidepressants; and (b) hypnotics and anxiolytics.

The surveys collected information about 'talking treatments' for mental health problems. Participants were handed a show-card listing interventions and asked: 'Looking at this card, could you tell me if you are having any counselling or therapy for a mental, nervous or emotional problem either at home, at a doctor's surgery, a health centre, hospital or clinic?' In the current analysis, participants who answered positively were counted as receiving a talking treatment. These were also asked 'Which type/s of counselling or therapy are you having?' Talking therapies from the show-card were subsequently grouped into the following categories: (a) psychotherapy, (b) behavioural or cognitive therapy, (c) counselling, (d) other therapy, including art, music or drama therapy, social skills training, marital or family therapy, and sex therapy.

The use of health and social services was recorded. The current analysis considers only primary care consultations. Participants were asked: 'In the past 12 months, have you spoken to a general practitioner or family doctor on your own behalf, either in person or by telephone about being anxious or depressed or a mental, nervous or emotional problem?' In all three surveys the presence of CMD was assessed using the Clinical Interview ScheduleRevised (CIS-R). ${ }^{18}$ This structured interview is designed for lay interviewers. Questions refer to neurotic symptoms experienced in the past week or month. In the current analyses we use the CIS-R total score, which reflects the overall severity of neurotic symptoms. The presence of CMD was defined as a total score of 12 and above. However, we also grouped participants' scores in the bands $0-5,6-11,12-17$ and $18+$ in order to examine links between the extent of CMD symptoms and service contact and treatment. Additionally, the participants' answers to the CIS-R were used to define the ICD-10 diagnosis ${ }^{19}$ of depressive disorder. The CIS-R does not differentiate between single and recurrent episodes, so the term 'depressive episode' includes depressive episode (F32) and recurrent depressive disorder (F33).

\section{Participants}

Data were weighted to allow for survey design and differences in non-response by age, gender, region and socioeconomic status, so that results are representative of the English household population of comparable age at the time of survey. ${ }^{9}$ Because the upper age limit varied between surveys, we restricted the age range to 16-64, a range covered in all three surveys. People assessed as having possible psychotic disorder (as described by Qassem $e t \mathrm{al}^{20}$ ) were excluded from analysis.

\section{Statistical analysis}

Men and women were analysed separately. We carried out a descriptive analysis of health service use and of pharmacological and psychological interventions by gender and survey. The svy proportion procedure in Stata 13.1 for OS X was used to obtain estimates and approximate linearisation-based standard errors, accounting for the complex survey design. Statistical comparisons used the adjusted Wald test with a two-sided 5\% significance level.

\section{Results}

\section{Sample characteristics}

After excluding participants with possible psychosis, 8615 adults aged 16 to 64 years were interviewed in English private households in 1993, 6126 in 2000 and 5385 in 2007. The prevalence of CMD in these samples was $14.3 \%$ in $1993,16.0 \%$ in 2000 and $16.0 \%$ in 2007. Missing data were minimal $(<0.3 \%)$ and did not affect our conclusions.

\section{Trends in health service use}

Prevalence of contact with a primary care physician for a psychological problem in the past year was $11.3 \%$ in 1993 , $12.0 \%$ in 2000 and $11.7 \%$ in 2007 . There was no statistically significant change between 1993 and 2000 or between 2000 and 2007 in the frequency of contact in the previous year for a psychological problem, regardless of gender or the presence of a CMD (Table 1). This pattern of no change persisted when participants were subdivided by CIS-R score, with the possible exception of men who scored 18 or more, where there was a borderline non-significant increase in those making contact of 10.3 percentage points from 36.6 to $46.9 \%$ between 1993 and 2000. As expected, in each survey primary care physicians contact increased pari passu with increasing CIS-R scores. Nevertheless, some people in the lowest scoring group had visited a primary care physician within the past year for a mental health problem, whereas even in the highest scoring group between a half and two-thirds of participants had not done so. However, among those with a research diagnosis of ICD-10 depressive episode, contact increased by about a third between 1993 and 2000, from 38.2 to $51.9 \%$ in men and from 49.5 to $68.2 \%$ in women, before stabilising (Table 1). This increase was statistically significant in women, but not in men.

Increased primary physician contact between 1993 and 2000 in people with $\mathrm{CMD}$ or depressive episode meriting treatment (CIS-R $\geqslant 18$ ) was paralleled by an increased use of antidepressants. This trebled among men with ICD-10 depressive episode, from 9.6 to $29.2 \%$, and doubled from 15.0 to $30.2 \%$ in women (Table 2). There was a similar increase in the group with a CMD, defined by CIS-R $\geqslant 12$, increasing from 4.8 to $12.0 \%$ in men, and from 6.3 to $16.2 \%$ in women. Although limited by small numbers in men, an increase was also apparent in non-cases, in whom antidepressant treatment was very rare in 1993 , but had increased to $1.1 \%$ in men and $3.2 \%$ in women by 2000 .

In those with the highest CIS-R scores (CIS-R $\geqslant 18$ ), antidepressant treatment was comparable in men and women across the three surveys. It should be noted that the gap in antidepressant receipt between the highest- and second-highest scoring CIS-R groups increased noticeably over the survey years. In addition, statistically significant increases in women between 1993 and 2000 opened a gender gap in treatment for the CIS-R scores from 6 to 17 (Fig. 1). The period 2000-2007 was one of stabilisation in antidepressant use, with scarcely any further change.

Small increases in the use of anxiolytics and hypnotics between 1993 and 2000 were followed by a reduction between 2000 and 2007, although these changes were non-significant (Table 3). The use of these medications was rare in non-cases of both genders, and in those with CMD, usage was similar in men and women, generally around $4 \%$ in the three surveys, and showing no consistent change. 


\begin{tabular}{|c|c|c|c|c|c|}
\hline & \multicolumn{3}{|c|}{$\%$ primary care physician contact (unweighted $n$ ) } & \multirow{2}{*}{$\begin{array}{c}\text { Increase 1993-2000, } \\
\%(95 \% \mathrm{Cl})\end{array}$} & \multirow{2}{*}{$\begin{array}{c}\text { Increase 2000-2007, } \\
\%(95 \% \mathrm{Cl})\end{array}$} \\
\hline & 1993 survey & 2000 survey & 2007 survey & & \\
\hline \multicolumn{6}{|l|}{ Men } \\
\hline No CMD & 4.8 & 4.5 & 3.8 & $-0.4(-1.6$ to 0.8$)$ & $-0.7(-1.9$ to 0.5$)$ \\
\hline CIS-R 1-5 & $3.5(113)$ & $3.0(65)$ & $1.9(37)$ & $-0.5(-1.6$ to 0.7$)$ & $-1.1(-2.0 \text { to }-0.1)^{*}$ \\
\hline CIS-R 6-11 & $10.9(81)$ & $11.2(58)$ & $13.2(45)$ & $0.3(-3.6$ to 4.1$)$ & $2.0(-2.8$ to 6.8$)$ \\
\hline CMD & 27.8 & 32.8 & 32.8 & $5.0(-2.1$ to 12.1$)$ & $0.4(-7.7$ to 7.8$)$ \\
\hline CIS-R 12-17 & $19.3(51)$ & $19.3(39)$ & $21.0(41)$ & $0.0(-8.2$ to 8.3$)$ & $1.7(-7.9$ to 11.2$)$ \\
\hline CIS-R 18+ & $36.6(84)$ & $46.9(98)$ & $44.8(88)$ & $10.3(-0.1$ to 20.6$)$ & $-2.0(-13.2$ to 9.2$)$ \\
\hline ICD-10 depressive episode & $38.2(34)$ & $51.9(42)$ & $50.1(43)$ & $13.6(-4.4$ to 31.7$)$ & $-1.8(-20.4$ to 16.8$)$ \\
\hline All & $7.3(329)$ & $8.2(260)$ & $7.4(211)$ & $0.9(-0.6$ to 2.3$)$ & $-0.8(-2.4$ to 0.7$)$ \\
\hline \multicolumn{6}{|l|}{ Women } \\
\hline No CMD & 9.8 & 9.7 & 9.2 & $-0.1(-1.7$ to 1.6$)$ & $-0.5(-2.3$ to 1.3$)$ \\
\hline CIS-R 1-5 & $6.6(202)$ & $6.5(145)$ & $6.2(129)$ & $-0.1(-1.7$ to 1.5$)$ & $-0.3(-1.9$ to 1.3$)$ \\
\hline CIS-R 6-11 & $18.0(196)$ & $19.5(141)$ & $18.4(118)$ & $1.6(-2.7$ to 5.8$)$ & $-1.1(-6.0$ to 3.7$)$ \\
\hline CMD & 40.1 & 41.4 & 46.0 & $1.3(-4.2$ to 6.8$)$ & $2.8(-3.0$ to 8.3$)$ \\
\hline CIS-R 12-17 & 31.9 (149) & $29.4(108)$ & $33.0(112)$ & $-2.5(-9.7$ to 4.7$)$ & $3.6(-3.9$ to 11.2$)$ \\
\hline CIS-R 18+ & $49.0(225)$ & 55.4 (189) & $54.1(186)$ & $6.4(-1.5$ to 14.3$)$ & $-1.3(-9.4$ to 6.9$)$ \\
\hline ICD-10 depressive episode & $49.5(78)$ & $68.2(75)$ & $65.2(82)$ & $18.7(5.3 \text { to } 32.1)^{\star * *}$ & $-3.0(-16.2$ to 10.1$)$ \\
\hline All & $15.2(772)$ & $15.7(583)$ & $16.1(545)$ & $0.5(-1.2$ to 2.4$)$ & $0.4(-1.6$ to 2.3$)$ \\
\hline
\end{tabular}

\begin{tabular}{|c|c|c|c|c|c|}
\hline & \multicolumn{3}{|c|}{$\%$ in receipt (unweighted $n$ ) } & \multirow{2}{*}{$\begin{array}{c}\text { Increase 1993-2000, } \\
\%(95 \% \mathrm{Cl})\end{array}$} & \multirow{2}{*}{$\begin{array}{c}\text { Increase 2000-2007 } \\
\%(95 \% \mathrm{Cl})\end{array}$} \\
\hline & 1993 survey & 2000 survey & 2007 survey & & \\
\hline \multicolumn{6}{|l|}{ Men } \\
\hline No CMD & 0.1 & 1.1 & 1.2 & $1.0^{\mathrm{b}}$ & $0.1(-0.6$ to 0.8$)$ \\
\hline CIS-R 1-5 & $0.1(2)$ & $0.6(14)$ & $0.5(13)$ & $0.5^{\mathrm{b}}$ & $-0.1(-0.6$ to 0.4$)$ \\
\hline CIS-R 6-11 & $0.3(2)$ & $3.1(16)$ & 4.5 (19) & $2.7^{\mathrm{b}}$ & $1.4(-1.4$ to 4.1$)$ \\
\hline CMD & 4.8 & 12.0 & 13.2 & $7.2(2.8 \text { to } 11.6)^{* *}$ & $1.1(-4.2$ to 6.5$)$ \\
\hline CIS-R 12-17 & $2.4(6)$ & $3.6(8)$ & $6.3(12)$ & $1.2(-2.3$ to 4.7$)$ & $2.7(-2.1$ to 7.5$)$ \\
\hline CIS-R 18+ & $7.3(18)$ & 20.9 (44) & $20.2(40)$ & $13.6(5.9 \text { to } 21.3)^{* * *}$ & $-0.8(-10.0$ to 8.6$)$ \\
\hline ICD-10 depressive episode & $9.6(10)$ & $29.2(22)$ & $31.1(24)$ & $19.5(5.9 \text { to } 33.2)^{\star *}$ & $1.9(-15.1$ to 19.0$)$ \\
\hline All & $0.6(28)$ & $2.5(82)$ & $2.6(84)$ & $1.9(1.1 \text { to } 2.6)^{* * *}$ & $0.1(-0.8$ to 1.1$)$ \\
\hline \multicolumn{6}{|l|}{ Women } \\
\hline No CMD & 0.2 & 3.2 & 4.0 & $3.0(2.3 \text { to } 3.7)^{\star * * *}$ & $0.8(-0.3$ to 1.9$)$ \\
\hline CIS-R 1-5 & $0.1(3)$ & $2.7(61)$ & $2.9(57)$ & $2.6^{\mathrm{b}}$ & $0.2(-0.9$ to 1.4$)$ \\
\hline CIS-R 6-11 & $0.4(5)$ & $4.8(39)$ & $7.2(50)$ & $4.4(2.6 \text { to } 6.1)^{\star \star * *}$ & $2.4(-0.3$ to 5.1$)$ \\
\hline $\mathrm{CMD}$ & 6.3 & 16.2 & 17.5 & $9.9(6.5 \text { to } 13.3)^{* * *}$ & $1.3(-2.9$ to 5.5$)$ \\
\hline CIS-R 12-17 & $3.5(20)$ & $10.4(43)$ & $13.1(49)$ & $6.9(3.1 \text { to } 10.7)^{\star * *}$ & $2.7(-2.4$ to 7.7$)$ \\
\hline CIS-R 18+ & $9.3(43)$ & $22.9(87)$ & $21.6(80)$ & $13.6(8.1 \text { to } 19.2)^{\star * *}$ & $-1.4(-7.9$ to 5.1$)$ \\
\hline ICD-10 depressive episode & $15.0(24)$ & $30.2(36)$ & $28.3(38)$ & $15.2(3.7 \text { to } 26.7)^{\star *}$ & $-1.9(-14.8$ to 11.0 \\
\hline All & $1.3(71)$ & $5.6(230)$ & $6.6(236)$ & $4.4(3.5 \text { to } 5.3)^{\star \star *}$ & $1.0(-0.3$ to 2.2$)$ \\
\hline
\end{tabular}

In men with a $\mathrm{CMD}$, there was a statistically significant increase in receipt of any type of talking therapy in the past year, from $4.8 \%$ in 1993 to $9.8 \%$ in 2000 (difference $5.0 \%, 95 \%$ CI 1.1-8.8), followed by stabilisation with $10.4 \%$ receiving treatment in 2007. In women with a CMD the corresponding increase was statistically non-significant, with rates of $6.8 \%$, $7.2 \%$ and $9.3 \%$ across the three surveys. Receipt of any talking therapy was somewhat greater among people with ICD-10 depressive episode, with an increasing trend across the surveys, from 7.8 to $14.1 \%$ and then $23.4 \%$ in men, and from 12.5 to $15.5 \%$ and then $20.1 \%$ in women. Pairwise differences between surveys were nonsignificant. In online Tables DS1-3 we provide tables equivalent to Tables 1-3 but based on data for both genders combined.

Counselling was the most frequent form of talking therapy, with between 3 and $5 \%$ of people with CMD reporting receipt in the past year: there was little difference between the genders and little evidence of trends between the surveys. The use of psychotherapy was also rare, being reported by very few noncases, and a small percentage of cases. Of participants with CMD, $0.1 \%$ in $1993,0.8 \%$ in 2000 and $1.8 \%$ in 2007 reported receiving cognitive-behavioural therapy (CBT) within the past year. Although these increases were significant when the genders were amalgamated, the actual numbers having CBT were very small, rising from 2 in 1993 to 22 in 2007. In all the surveys, small numbers of people with a CMD were receiving other therapies, such as sex or marital therapy, art or music therapy, group meditation or social skills training.

When psychoactive medication and talking treatments were combined, rates increased markedly in those with CMD between 1993 and 2000, from 11.4 to $20.1 \%$ in men and from 13.6 to 


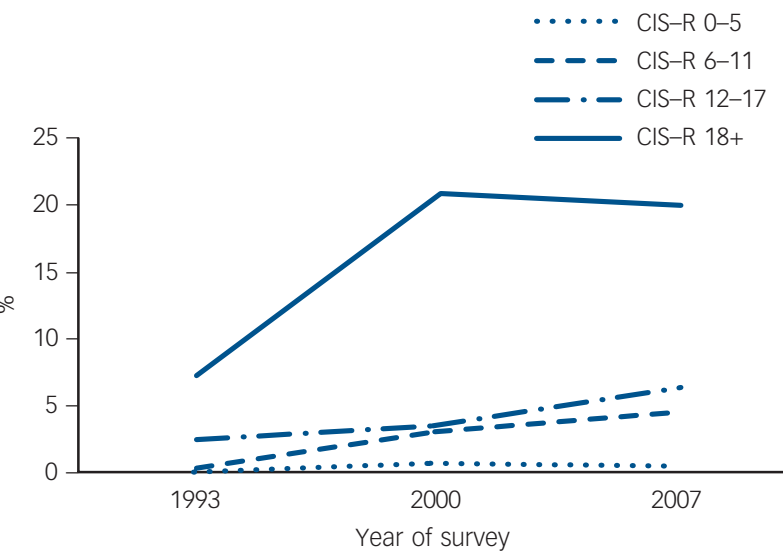

(b)

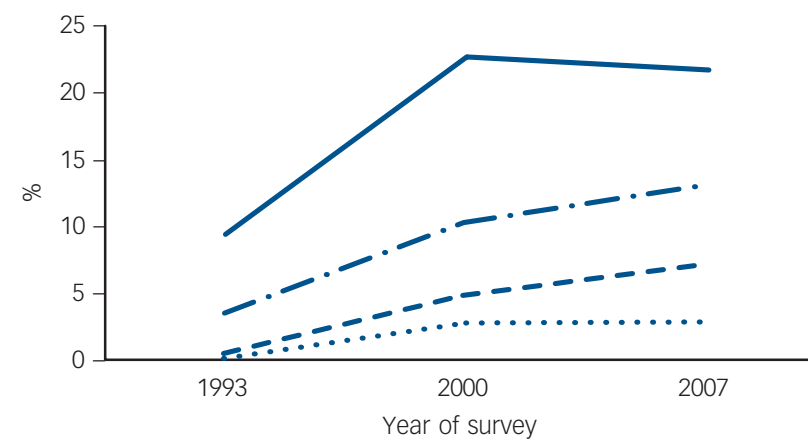

Fig. 1 Change in antidepressant use over three surveys: 1993, 2000, 2007 in (a) men and (b) women.

CIS-R Clinical Interview Schedule - Revised.

$22.2 \%$ in women, followed by stabilisation. In $2007,20.6 \%$ of women and $24.3 \%$ of men with CMD received some form of treatment. In men with ICD-10 depression, the percentage receiving any treatment more than doubled between 1993 and 2000, from 17.5 to $40.9 \%$, and $45.5 \%$ received treatment in 2007 . The trend for women was similar, with corresponding percentages of $25.3 \%, 38.6$ and $40.4 \%$.

\section{Discussion}

\section{Main findings}

Against a background of a largely stable prevalence of CMDs, there was little change in primary care physician contact for a psychological problem over the period from 1993 to 2007. However, treatment with antidepressants increased significantly, nearly trebling between 1993 and 2000, following which there was no further increase between 2000 and 2007. Even so, only a sixth or so of those with a CMD and less than a third of those with a depressive episode were receiving antidepressants by 2007 . There was limited evidence of an increase in talking treatments between 1993 and 2007, but take-up of these treatments remained quite rare. Even in 2007, a large majority of people with CMD, and a majority even of those with depressive episode received no treatment for their disorder.

\section{Strengths and limitations}

A major strength of this study, not available in similar studies around the world, is consistent measures of health service use, combined with standardised psychiatric evaluation based on identical measures, across three large representative cross-sectional surveys of the English household population spanning 15 years. It includes the many individuals who are symptomatic but do not seek treatment. It is thus an essential adjunct to studies using routine data from self-selected general practices, which are subject to variations in help-seeking behaviour by patients, and in diagnostic and reporting behaviour by primary care physicians.

Although national surveys have the advantage of eliciting data from large representative samples, the declining response rates in the successive surveys are a matter for concern. ${ }^{21}$ Nevertheless, great care was taken to reduce biases in these surveys by the use of a sophisticated weighting procedure. Moreover, recent non-response analyses of surveys from Scandinavian countries (especially those using population registers as a sampling frame)

Table 3 Participants aged 16-64 in three surveys: receipt of anxiolytic/hypnotic medication ${ }^{\mathrm{a}}$

\begin{tabular}{|c|c|c|c|c|c|}
\hline & \multicolumn{3}{|c|}{$\%$ in receipt (unweighted $n$ ) } & \multirow{2}{*}{$\begin{array}{c}\text { Increase 1993-2000, } \\
\%(95 \% \mathrm{Cl})\end{array}$} & \multirow{2}{*}{$\begin{array}{c}\text { Increase } 2000-2007 \text {, } \\
\%(95 \% \mathrm{Cl})\end{array}$} \\
\hline & 1993 survey & 2000 survey & 2007 survey & & \\
\hline \multicolumn{6}{|l|}{ Men } \\
\hline No CMD & $0.1(6)$ & $0.4(12)$ & $0.3(5)$ & $0.3(0.0 \text { to } 0.7)^{*}$ & $-0.1(-0.6$ to 0.4$)$ \\
\hline CIS-R 0-5 & $0.1(3)$ & $0.1(4)$ & $0.2(2)$ & $0^{\mathrm{b}}$ & $0.1^{\mathrm{b}}$ \\
\hline CIS-R 6-11 & $0.4(3)$ & $1.8(8)$ & $1.1(3)$ & $1.4^{\mathrm{b}}$ & $-0.7^{\mathrm{b}}$ \\
\hline CMD & 4.3 & 5.5 & $3.5(\mathrm{~N})$ & $1.2(-2.0$ to 4.5$)$ & $-2.0(-5.3$ to 1.4$)$ \\
\hline CIS-R 12-17 & $3.1(7)$ & $0.6(1)$ & $0.7(1)$ & $-2.4^{b}$ & $0.1^{\mathrm{b}}$ \\
\hline CIS-R 18+ & $5.5(16)$ & $10.6(23)$ & $6.4(13)$ & $5.1(-0.9$ to 11.2$)$ & $-4.2(-10.7$ to 2.2$)$ \\
\hline ICD-10 depressive episode & $8.5(10)$ & $14.1(11)$ & $11.1(9)$ & $5.6(-4.7$ to 15.9$)$ & $-3.0(-14.7$ to 8.8$)$ \\
\hline All & $0.6(29)$ & $1.1(36)$ & $0.7(19)$ & $0.5(0.0 \text { to } 1.1)^{\star}$ & $-0.4(-1.0$ to 0.3$)$ \\
\hline \multicolumn{6}{|l|}{ Women } \\
\hline No CMD & $0.1(5)$ & $0.6(23)$ & $0.3(9)$ & $0.5(0.2 \text { to } 0.9)^{* * *}$ & $-0.3(-0.7 \text { to } 0.0)^{*}$ \\
\hline CIS-R 0-5 & $0.1(3)$ & $0.5(13)$ & $0.3(6)$ & $0.4^{\mathrm{b}}$ & $-0.2(-0.6 \text { to } 0.2)^{*}$ \\
\hline CIS-R 6-11 & $0.2(2)$ & $1.1(10)$ & $0.4(3)$ & $0.9^{\mathrm{b}}$ & $-0.7^{b}$ \\
\hline CMD & 4.3 & 4.5 & 2.7 & 0.2 ( -1.8 to 2.2$)$ & $-1.8(-3.8$ to 0.2$)$ \\
\hline CIS-R 12-17 & $1.9(12)$ & $2.2(10)$ & $1.5(5)$ & $0.3(-1.6$ to 2.1$)$ & $-0.7(-2.7$ to 1.3$)$ \\
\hline CIS-R 18+ & $6.8(36)$ & $7.1(25)$ & $3.8(16)$ & $0.3(-3.4$ to 4.1$)$ & $-3.3(-6.8$ to 0.1$)$ \\
\hline ICD-10 depressive episode & $7.0(12)$ & $7.4(8)$ & $7.7(11)$ & $0.4(-6.3$ to 7.1$)$ & $0.3(-6.8$ to 7.4$)$ \\
\hline All & $0.9(53)$ & $1.4(58)$ & $0.8(30)$ & 0.5 (0.0 to 1.0$)^{*}$ & $-0.6(-1.1 \text { to } 0.0)^{*}$ \\
\hline \multicolumn{6}{|c|}{$\begin{array}{l}\text { CMD, common mental disorder. } \\
\text { a. Probable cases of psychosis excluded. Data are weighted to represent the English household population of comparable age } \\
\text { b. Insufficient data for confidence intervals. } \\
* P<0.05,{ }^{* * * P<0.001} \text {. }\end{array}$} \\
\hline
\end{tabular}


indicate very little non-response bias on a wide variety of physical and mental health measures. ${ }^{22-24}$

The surveys did not include homeless people or those living in institutions, who are likely to be older and in poorer mental health than those in private households. These subgroups are, however, very small relative to the general population, and the exclusions remained the same with each wave, so trends will not have been affected.

\section{Interpretation of our findings}

Our results are broadly consistent with routine database ${ }^{25}$ and prescription $^{26}$ data, which also indicate a slowing of the increase in antidepressant prescribing in the UK in the early 2000s, after the rapid increases of the 1980s and 1990s. The combination of a stable prevalence of psychological morbidity with increased rates of treatment between 1993 and 2000 is also consistent with findings in the US National Comorbidity Surveys. ${ }^{5}$

The absence of treatment in people identified as having CMDs may not represent a failure of treatment practice. Given that many episodes of CMD are self-limiting, a period of watchful waiting is reasonable before initiating treatment, as recommended in the current National Institute for Health and Care Excellence (NICE) guidelines. ${ }^{27}$ On the other hand, the levels of treatment identified in these surveys really were very low. Even in the later surveys, less than a third of people with a research diagnosis of a depressive episode were receiving antidepressant treatment, and considerably fewer were being treated with psychological interventions. Overall, only one in four of those with a CMD was receiving treatment of any kind in 2000 and in 2007.

There is some reassurance in our finding that the major determinant of contact and treatment is severity: the use of antidepressants clearly increases proportionately as the level of psychological disturbance increases. Moreover, the increase in antidepressant receipt over time was most apparent in those with the most severe disorder. However, the strong message from our results is that too few people are getting treatment for their disorders. Our results point to a failure of contact with primary care services, compounded by current undertreatment. But we cannot say to what extent this is because of underrecognition by practitioners or by patient behaviour driven, for example, by stigma.

In each survey, there was some receipt of antidepressants in people who scored below the case threshold on the CIS-R. The increased receipt seen in cases in successive surveys was also seen in non-cases, such that, by $2007,1.2 \%$ of male non-cases and $4 \%$ of female non-cases were in receipt of antidepressants. In 1993 only $13.7 \%$ of antidepressant treatments were being given to people who were non-cases, a figure rising to $43.1 \%$ in 2000 , and $45.4 \%$ in 2007 . This indeed has the appearance of a significant shift in practice.

The presence of treatment in people with no identified disorder might seem to represent overtreatment, but the APMS records symptoms at the time of survey, and an unknown number are likely to be in the maintenance phase of treatment, as now recommended in the NICE guidelines. ${ }^{27}$ Thus, if antidepressant treatment is effective in reducing symptoms to non-case levels in, say, a mean of 3 months, and maintenance treatment is prescribed for a further 3 months, one would expect half of those treated to be non-cases at any point in time, approximately what we found in the two later surveys. The emerging treatment of those with lower CIS-R scores in women, as seen in Fig. 1 may indicate treatment success, against a background of greater resistance to treatment in men. Nevertheless, worries remain about whether the treatment of non-cases may sometimes represent misdiagnosis or a failure of monitoring by prescribers. It may also raise concerns about dependency.

Some increases in use of antidepressants between 1993 and 2000 may be attributable to the Defeat Depression Campaign of 1992-1996 and related national policy initiatives to support improved assessment and management of depression in primary care. ${ }^{13}$ Increases in prescribing may also be the result of other factors external to the patient, such as shifts in professional opinion and health policy, the development of diagnostic manuals, and National Health Service and UK-adapted World Health Organization (WHO) guidelines. ${ }^{28}$ Such changes include screening approaches, pharmaceutical company marketing efforts (including direct-to-consumer marketing ${ }^{7}$ ) and the availability of treatments. Moore and colleagues ${ }^{25}$ have shown that increases in prescribing in the UK were largely the result of increased progression to long-term prescribing in a small number of patients, at least in incident cases. This is consistent with the maintenance guidelines from NICE. ${ }^{27}$

The use of sedatives (anxiolytics or hypnotics) showed minor, inconsistent and non-significant changes. Only a few per cent of those with a disorder were taking these drugs and the proportion of non-cases doing so was very small. Few people were receiving counselling or psychotherapy. Although there were significant changes between the surveys, the numbers involved were very small: by 2007 about 1 in 40 people with CMD reported being treated in this way. However, even the 2007 survey was too early to capture the full benefit of the British national Initiative for Access to Psychological Treatments (IAPT), which includes a nationwide roll-out of psychological therapy services for adults. ${ }^{14}$ The 2007 survey thus provides a benchmark for future evaluation of the impact of IAPT.

Our analyses suggest some improvement in levels of treatment over the three surveys, but little difference in the levels of disorder. Similar findings have been reported from other countries. ${ }^{29,30}$ This might seem disappointing, but needs to be seen in the context of a number of possible limitations. First, there is the number of cases that must be treated in order to achieve one extra recovery (number needed to treat). For both antidepressant therapy and CBT, this is around seven. ${ }^{31,32}$ Thus, even if everyone with a CMD were treated with medication or psychological intervention (and they clearly are not), the prevalence would only decline by one in seven. Second, the weight of evidence from meta-analyses of placebo-controlled trials suggests that antidepressant drugs have little effect in mild depression ${ }^{31,33}$ and most cases in the general population are mild. Finally, changes in unknown or unmeasured factors could have acted to cancel out possible benefits of improved treatment.

\section{Implications}

Depression continues to be a leading and rising cause of disability worldwide: the Global Burden of Disease (GBD) studies underlined the 'large unrecognised burden of mental illness in developed and developing countries' $-8.5 \%$ of Disability Adjusted Life Years (DALYs) in the GBD 1990 study and $10.1 \%$ in the GBD 2010 study. ${ }^{34}$ Attention was drawn to 'the urgent need for identification and implementation of effective and affordable strategies for this set of problems., ${ }^{35}$ It is surely time to ask whether more can be done by expanding on current strategies.

Both chronic care and collaborative care models ${ }^{36,37}$ have potential for improving routine screening and diagnosis of depressive disorders, by increasing the use of evidence-based protocols for the proactive management of diagnosed depressive disorders; and by improving clinical and community support for active patient engagement in treatment goal-setting and self-management. 
Collaborative care is a multicomponent, healthcare system-level intervention that uses case managers to link primary care providers, patients and mental health specialists. In addition to case management support, primary care providers receive consultation and decision support from mental health specialists (i.e. psychiatrists and psychologists). ${ }^{35}$ Case managers provide links between primary care providers, patients and mental health specialists as necessary. The chronic care model, ${ }^{37}$ comprising structured, frequent, proactive care review of patients with chronic depression in primary care, has been successfully applied in diabetes $^{38}$ and hypertension. ${ }^{39}$ However, the development of a chronic care model for mental disorders is premature without reliable screening protocols and a clear evidence base for treatments, both currently lacking. Others have shown high levels of comorbidity with physical health problems. ${ }^{2}$ Although there are barriers to implementation, the potential economic and health benefits of integrated models of care are considerable, ${ }^{40}$ but again will be hampered by weaknesses in the evidence concerning assessment and treatment of mental disorders. An expanded research and professional education effort is required to underpin development of chronic and collaborative models of primary care for mental disorders.

The elimination of undertreatment ${ }^{41}$ is clearly an important humanitarian objective, and is being pursued energetically in Australia, particularly with the use of web-based resources. ${ }^{40,42,43}$ Nevertheless, such initiatives can have only a moderate impact. The public health imperative of reducing the population burden of CMDs may therefore be served better through interventions at the population level. Socioeconomic interventions are hard to mount, and in any case are often vitiated by the unintended consequences of other politically determined changes, for instance changes in employment levels and the characteristics of the work environment. ${ }^{44-46}$ Moreover, socioeconomic interventions may be less effective because area effects on risk of CMDs are relatively unimportant compared with individual- and household-level effects. ${ }^{47-49}$ The most significant predictor of depression in adults is prior subthreshold depression, ${ }^{31,50}$ but population-based approaches for supporting adults with subthreshold depression have hardly been considered. A potentially promising model for reducing undertreatment has been demonstrated in a psychological treatment trial for postnatal depression ${ }^{51}$ based on retraining health visitors. Expanding the role of primary healthcare front-line practitioners to include effective psychological treatment skills ${ }^{51}$ without the need for referral to separate services may also be more generally acceptable ${ }^{52}$ and could even lead to depression prevention effects, for example, delivered by community midwives and health visitors. ${ }^{51,53,54}$

In conclusion, while pharmacological treatments will have a developing role, the experience of the era of selective serotonin reuptake inhibitors outlined here and elsewhere shows they are unlikely to dent the burden of mental disorders substantially in the short and medium term. We have found that even in those with more severe disorders (CIS-R 18+), many have had no recent contact with a primary care physician, whereas many others make contact but do not receive treatment. This may reflect barriers including stigma, demoralisation, doubts about efficacy and concerns about polypharmacy and real or perceived side-effects. Measurable effects on prevalence and health burden at the population level will require not just one or two, as now, but instead a mix of many approaches, requiring pharmacological, psychological and computer-based interventions at the individual level, together with public health measures, including those integrating preventive mental healthcare within general medical care at key stages in the life course..$^{51,53-55}$ Responding to this challenge remains an economic and humanitarian imperative.
Nicola Spiers, PhD, Department of Health Sciences, University of Leicester Leicester, UK; Tarik Qassem, MD, Division of Mental Health and Well-being University of Warwick, Coventry, UK, and Okasha Institute of Psychiatry, Ain Shams University, Cairo, Egypt, and Black Country Partnership NHS Foundation Trust, West Bromwich, UK; Paul Bebbington, PhD, FRCP, FRCPsych, Division of Psychiatry, Faculty of Brain Sciences, University College London, London, UK; Sally McManus MSc, NatCen for Social Research, London, UK; Michael King, PhD, Division of Psychiatry, Faculty of Brain Sciences, University College London, London, UK; Rache Jenkins, FRCPsych, Institute of Psychiatry at Kings College, London, UK; Howard Meltzer (deceased), PhD, Department of Health Sciences, University of Leicester, Leicester; Traolach S. Brugha, FRCPsych, Department of Health Sciences, University of Leicester, Leciester; UK

Correspondence: Traolach Brugha, Department of Health Sciences, University of Leicester, Centre for Medicine, University Road, Leicester LE1 7RH, UK. Email: tsb@le.ac.uk

First received 31 Aug 2015, final revision 8 Dec 2015, accepted 12 Dec 2015

\section{Funding}

The National Psychiatric Morbidity surveys were funded by the Department of Health, England, to the University of Leicester (1993-2007) and to the Office for National Statistics (1993-2000) and NatCen Social Research (2007), and via the Health and Social Care Information Centre, Leeds (2007).

\section{Acknowledgements}

In grateful memory of our colleague Howard Meltzer, and with thanks to the participants and interviewers of the APMS 1993 and 2000 and the Adult Psychiatric Morbidity Survey 2007

\section{References}

1 Centre for Mental Health. The Economic and Social Costs of Mental Health Problems in 2009/10. Centre for Mental Health, 2015

2 weich S, Bebbington P, Rai D, Stranges S, McBride O, Spiers N, et al. The population impact of common mental disorders and long-term physical conditions on disability and hospital admission. Psychol Med 2013; 43: 921-31.

3 Compton WM, Conway KP, Stinson FS, Grant BF. Changes in the prevalence of major depression and comorbid substance use disorders in the United States between 1991-1992 and 2001-2002. Am J Psychiatry 2006; 163: 2141-7

4 Marcus SC, Olfson M. National trends in the treatment for depression from 1998 to 2007. Arch Gen Psychiatry 2010; 67: 1265-73.

5 Kessler RC, Demler O, Frank RG, Olfson M, Pincus HA, Walters EE, et al. Prevalence and treatment of mental disorders, 1990 to 2003. N Engl J Med 2005; 352: 2515-23.

6 Spiers N, Bebbington P, McManus S, Brugha TS, Jenkins R, Meltzer $\mathrm{H}$. Age and birth cohort differences in the prevalence of common mental disorder in England: National Psychiatric Morbidity Surveys 1993-2007. Br J Psychiatry 2011; 198: 479-84.

7 Dowrick C, Frances A. Medicalising unhappiness: new classification of depression risks more patients being put on drug treatment from which they will not benefit. BMJ 2013; 347: 77140 .

8 Jenkins $\mathrm{R}$, Meltzer $\mathrm{H}$, Bebbington $\mathrm{P}$, Brugha $\mathrm{T}$, Farrell $\mathrm{M}$, McManus $\mathrm{S}$, et al. The British Mental Health Survey Programme: achievements and latest findings. Soc Psychiatry Psychiatr Epidemiol 2009; 44: 899-904.

9 McManus $\mathrm{S}$, Meltzer $\mathrm{H}$, Brugha $\mathrm{T}$, Bebbington $\mathrm{P}$, Jenkins R. Adult Psychiatric Morbidity in England, 2007. Results of a Household Survey. The NHS Information Centre for Health and Social Care, 2009.

10 Meltzer H, Gill B, Petticrew M, Hinds K. OPCS Surveys of Psychiatric Morbidity in Great Britain. Report 1: The Prevalence of Psychiatric Morbidity among Adults Living in Private Households. HMSO, 1995.

11 Singleton N, Bumpstead R, O'Brien M, Lee A, Meltzer H. Psychiatric Morbidity Among Adults Living in Private Households. TSO (The Stationery Office), 2001.

12 Calem M, Bisla J, Begum A, Dewey M, Bebbington PE, Brugha T, et al. Increased prevalence of insomnia and changes in hypnotics use in England over 15 years: analysis of the 1993, 2000, and 2007 National Psychiatric Morbidity Surveys. Sleep 2012; 35: 377-84.

13 Brugha TS, Bebbington PE, Singleton N, Melzer D, Jenkins R, Lewis G, et al. Trends in service use and treatment for mental disorders in adults throughout Great Britain. Br J Psychiatry 2004; 185: 378-84. 
14 Clark DM. Implementing NICE guidelines for the psychological treatment of depression and anxiety disorders: the IAPT experience. Int Rev Psychiatry 2011; 23: 318-27.

15 Baker R, Bradburn N, Johnson R. Computer-assisted personal interviewing. an experimental evaluation of data quality and cost. J Off Statist 1995; 11: 413-31.

16 British Medical Association \& Royal Pharmaceutical Society of Great Britain British National Formulary. BMJ, 2000.

17 McManus S, Meltzer H, Brugha T, Bebbington P, Jenkins R. Adult Psychiatric Morbidity in England: Results of a Household Survey: Appendices and Glossary. NHS Information Centre for Health and Social Care, 2009.

18 Lewis G, Pelosi AJ, Araya R, Dunn G. Measuring psychiatric disorder in the community: a standardized assessment for use by lay interviewers. Psychol Med 1992; 22: 465-86.

19 World Health Organization. The ICD-10 Classification of Mental and Behavioural Disorders: Clinical Descriptions and Diagnostic Guidelines. WHO 1992.

20 Qassem T, Bebbington P, Spiers N, McManus S, Jenkins R, Dein S. Prevalence of psychosis in black ethnic minorities in Britain: analysis based on three national surveys. Soc Psychiatry Psychiatr Epidemiol 2015; 50: 1057-64.

21 De Leeuw E, Heer W. Trends in household survey response: a longitudinal and international comparison. In Survey Nonresponse (ed R Groves): 41-54. Wiley, 2002.

22 de Winter AF, Oldehinkel AJ, Veenstra R, Brunnekreef JA, Verhulst FC, Ormel J. Evaluation of non-response bias in mental health determinants and outcomes in a large sample of pre-adolescents. Eur J Epidemiol 2005; 20: $173-81$.

23 Korkeila K, Suominen S, Ahvenainen J, Ojanlatva A, Rautava P, Helenius $\mathrm{H}$, et al. Non-response and related factors in a nation-wide health survey. Eur J Epidemiol 2001; 17: 991-9.

24 Sogaard AJ, Selmer R, Bjertness E, Thelle D. The Oslo Health Study: the impact of self-selection in a large, population-based survey. Int J Equity Health 2004; 3: 3

25 Moore M, Yuen HM, Dunn N, Mullee MA, Maskell J, Kendrick T. Explaining the rise in antidepressant prescribing: a descriptive study using the general practice research database. BMJ 2009; 339: b3999.

26 Lockhart $P$, Guthrie $B$. Trends in primary care antidepressant prescribing 1995-2007: a longitudinal population database analysis. Br J Gen Prac 2011 61: e565-72.

27 National Institute for Health and Care Excellence. Depression in Adults: Recognition and Management (CG90). NICE, 2009.

28 Collaborating Centre for Mental Health. WHO Guide to Mental and Neurological Health in Primary Care. Royal Society of Medicine Press, 2004.

29 Mojtabai R, Jorm AF. Trends in psychological distress, depressive episodes and mental health treatment-seeking in the United States: 2001-2012. J Affect Disord 2015; 174: 556-61.

30 Patten SB, Williams JV, Lavorato DH, Bulloch AG, Wiens $K$, Wang J. Why is major depression prevalence not changing? J Affect Disord 2015; 190: 93-7.

31 Fournier JC, DeRubeis RJ, Hollon SD, Dimidjian S, Amsterdam JD, Shelton RC et al. Antidepressant drug effects and depression severity: a patient-level meta-analysis. JAMA 2010; 303: 47-53.

32 Cuijpers $\mathrm{P}$, Smit F. Subthreshold depression as a risk indicator for major depressive disorder: a systematic review of prospective studies. Acta Psychiatr Scand 2004; 109: 325-31.

33 Barbui C, Cipriani A, Patel V, Ayuso-Mateos JL, van Ommeren M. Efficacy of antidepressants and benzodiazepines in minor depression: systematic review and meta-analysis. Br J Psychiatry 2011; 198: 11-6.

34 Murray CJ, Vos T, Lozano R, Naghavi M, Flaxman AD, Michaud C, et al. Disability-adjusted life years (DALYS) for 291 diseases and injuries in 21 regions, 1990-2010: a systematic analysis for the Global Burden of Disease Study 2010. Lancet 2012; 380: 2197-223.

35 Vos T, Flaxman AD, Naghavi M, Lozano R, Michaud C, Ezzati M, et al. Years lived with disability (YLDS) for 1160 sequelae of 289 diseases and injuries
1990-2010: a systematic analysis for the Global Burden of Disease Study 2010. Lancet 2012; 380: 2163-96.

36 Thota AB, Sipe TA, Byard GJ, Zometa CS, Hahn RA, Knight-Eily LR, et al. Collaborative care to improve the management of depressive disorders: a community guide systematic review and meta-analysis. Am J Prev Med 2012; 42: $525-38$

37 Buszewicz M, Griffin M, McMahon EM, Beecham J, King M. Evaluation of a system of structured, pro-active care for chronic depression in primary care: a randomised controlled trial. BMC Psychiatry 2010; 10: 61.

38 Stellefson M, Dipnarine K, Stopka C. The chronic care model and diabetes management in US primary care settings: a systematic review. Prev Chronic Dis 2013; 10: E26.

39 Green BB, Cook AJ, Ralston JD, Fishman PA, Catz SL, Carlson J, et al. Effectiveness of home blood pressure monitoring, web communication, and pharmacist care on hypertension control: a randomized controlled trial. JAMA 2008; 299: 2857-67.

40 Foley T. Bridging the Gap: The Financial Case for a Reasonable Rebalancing of Health and Care Resources. Royal College of Psychiatrists, Centre for Mental Health, 2013.

41 Kohn R, Saxena S, Levav I, Saraceno B. The treatment gap in mental health care. Bull World Health Organ 2004; 82: 858-66.

42 Andrews G, Titov N. Changing the face of mental health care through needs-based planning. Aust Health Rev 2007; 31 (suppl 1): 122-8.

43 Andrews $\mathrm{G}$, Titov $\mathrm{N}$. Is internet treatment for depressive and anxiety disorders ready for prime time? Med J Aust 2010; 192 (suppl 11): 45-7.

44 Ford E, Clark C, McManus S, Harris J, Jenkins R, Bebbington P, et al. Common mental disorders, unemployment and welfare benefits in England. Public Health 2010; 124: 675-81.

45 Meltzer $\mathrm{H}$, Bebbington $\mathrm{P}$, Brugha $\mathrm{T}$, Jenkins R, McManus $\mathrm{S}$, Stansfeld $\mathrm{S}$. Job insecurity, socio-economic circumstances and depression. Psychol Med 2010; 40: 1401-7.

46 Stansfeld SA, Pike C, McManus S, Harris J, Bebbington P, Brugha T, et al. Occupations, work characteristics and common mental disorder. Psychol Med 2013; 43: 961-73.

47 Weich S, Twigg L, Holt G, Lewis G, Jones K. Contextual risk factors for the common mental disorders in Britain: a multilevel investigation of the effects of place. J Epidemiol Community Health 2003; 57: 616-21.

48 weich S, Twigg L, Lewis G, Jones K. Geographical variation in rates of common mental disorders in Britain: prospective cohort study. Br J Psychiatry 2005; 187: 29-34.

49 weich S. Absence of spatial variation in rates of the common mental disorders. J Epidemiol Community Health 2005; 59: 254-7.

50 Judd LL, Schettler PJ, Akiskal HS. The prevalence, clinical relevance, and public health significance of subthreshold depressions. Psychiatr Clin North Am 2002; 25: 685-98.

51 Morrell CJ, Slade P, Warner R, Paley G, Dixon S, Walters SJ, et al. Clinical effectiveness of health visitor training in psychologically informed approaches for depression in postnatal women: pragmatic cluster randomised trial in primary care. BMJ 2009; 338: a3045.

52 Bellon JA, Moreno-Kustner B, Torres-Gonzalez F, Monton-Franco C, GildeGomez-Barragan MJ, Sanchez-Celaya M, et al. Predicting the onset and persistence of episodes of depression in primary health care. The predictD-Spain study: methodology. BMC Public Health 2008; 8: 256.

53 Brugha TS, Smith J, Austin J, Bankart J, Patterson M, Lovett C, et al. Can community midwives prevent antenatal depression? An external pilot study to test the feasibility of a cluster randomized controlled universal prevention trial. Psychol Med 2015; 20: 1-12.

54 Brugha TS, Morrell CJ, Slade P, Walters SJ. Universal prevention of depression in women postnatally: cluster randomized trial evidence in primary care. Psychol Med 2011; 41: 739-48.

55 Tan L, Wang MJ, Modini M, Joyce S, Mykletun A, Christensen $\mathrm{H}$, et al Preventing the development of depression at work: a systematic review and meta-analysis of universal interventions in the workplace. BMC Med 2014; 12: 74 . 